\title{
IDENTIFIKASI BAKAT ISTIMEWA PANAHAN DI KABUPATEN SLEMAN
}

\author{
Yudik Prasetyo, Ahmad Nasrulloh, Komarudin \\ Fakultas Ilmu Keolahragaan \\ Universitas Negeri Yogyakarta
}

\begin{abstract}
This study aims to determine the potential of athletes who have talent in archery in Sleman Regency at the age of 7-12 years.

It is descriprive quantitative research with survey methods and data were collected through tests and measurements. The population of this study involved all archery athletes at the age of 7-12 years in the Sleman Regency. The sample used in this study was 40 children. The data collection techniques used were anthropometric tests, physical ability tests, and archery skill tests.

The data were analysed descriptive qualtitatively using precentages. The results show that there were 5 children (12.5\%) categorized as very talented, 24 children (60\%) as talented, and 11 children (27.5\%) as satisfactorily talented.
\end{abstract}

Keywords : identification, talent, archery.

\begin{abstract}
ABSTRAK
Penelitian ini bertujuan untuk mengetahui potensi atlet yang memiliki bakat pada cabang olahraga panahan di Kabupaten Sleman pada usia 7-12 tahun tahun.

Penelitian ini merupakan penelitian deskriptif kuantitatif dengan metode survei dan teknik pengumpulan data dengan tes dan pengukuran. Populasi penelitian ini melibatkan seluruh atlet panahan usia 7-12 tahun di wilayah Kabupaten Sleman. Sampel yang digunakan dalam penelitian ini sebanyak 40 anak. Teknik pengambilan data menggunakan tes antropometri, tes kemampuan fisik, dan tes kemampuan ketrampilan panahan.

Teknik analisis data menggunakan teknik analisis deskriptif kuantitatif dengan persentase. Hasil penelitian menunjukkan bahwa kemampuan atlet panahan di Kabupaten Sleman dalam kategori sangat berbakat sebanyak 5 anak (12,5\%), berbakat sebanyak 24 anak (60\%), dan cukup berbakat sebanyak 11 anak $(27,5 \%)$.
\end{abstract}

Kata kunci: identifikasi, bakat, panahan

\section{PENDAHULUAN}

Panahan adalah olahraga keteram-

pilan motorik halus dan kasar, di mana

kesuksesan ditentukan oleh kapasitas untuk menembak target berulang kali pre-

sisi dan akurasi yang luar biasa (Taha

Zahari et al, 2018: 185). Salah satu upaya mendapatkan atlet panahan berbakat, ada- 
lah melakukan pemanduan bakat sejak usia dini. Program pemanduan dan pengembangan bibit atlet berbakat di negaranegara yang maju prestasinya telah dilaksanakan dengan mendapatkan dukungan sumber-sumber daya memadai, termasuk dari dana pemerintah, masyarakat, serta dukungan kepakaran melalui pendekatan ilmiah secara lintas dan inter disiplin.

Permasalahan yang terjadi di klubklub panahan adalah salah satunya kurangnya perhatian dalam pemanduan bakat, sehingga sulit untuk mencari bibit-bibit panahan, padahal potensi bagi pengembangan olahraga panahan sendiri masih terbuka lebar. Anak-anak Sekolah Dasar (SD) masih banyak memilih olahraga yang sifatnya permainan beregu seperti sepakbola, bola voli, bola basket, dll. Anak-anak yang ingin mengikuti olahraga panahan masih terkendala dengan peralatan, karena harganya relatif lebih mahal dibanding dengan peralatan olahraga yang sifatnya beregu. Sedangkan sangat jelas bahwa pencapaian prestasi akan dapat dipetik apabila dimulai sejak usia dini, namun kebanyakan orang mengenal/belajar panahan sudah remaja.

Sistem pelaksanaan pemanduan bakat bukan merupakan sesuatu yang berdiri sendiri, melainkan merupakan perpaduan dari berbagai aspek usaha. Berkaitan dengan hal tersebut, maka perlu adanya kajian mengenai bagaimana mengembangkan dan mengefektifkan sistem pelaksanaan pemanduan bakat dengan mengoptimalkan potensi yang ada (Adhi Purnomo, 2014: 29).

Usia anak-anak dalam olahraga panahan dibagi menjadi 2, yaitu 1) pra yunior dengan usia di bawah 12 tahun, dan 2) yunior A usia 12-15 tahun. Untuk pra junior tembakan panah yang dilakukan adalah jarak 10, 15, dan $20 \mathrm{~cm}$. Sedangkan junior A dengan jarak 20, 30, dan 40 meter. Kemampuan memanah dengan jarak yang telah disesuaikan dengan usia tersebut belum tentu dapat dilakukan oleh semua anak, namun bagi yang mempunyai bakat memanah dan berlatih secara kon- 
tinu akan mudah memanahkan dengan jarak tersebut.

Sejalan dengan pertumbuhan dan perkembangan cabang olahraga panahan, maka untuk mencapai prestasi harus selalu diupayakan semakimal mungkin. Mencapai prestasi panahan secara maksimal tidaklah mudah. Untuk mencapai prestasi yang tinggi harus dipersiapkan sejak dini, usaha keras dan didukung faktor-faktor yang dapat mempengaruhi pencapaian prestasi. Pemanduan bakat dan pelatihan sejak usia dini harus dilakukan, karena proses untuk mencapai prestasi membutuhkan waktu yang lama. Pemanduan bakat dan pelatihan sejak usia dini memungkinkan untuk mencapai prestasi seperti yang diharapkan. Hal ini penting sekali untuk diketahui, karena pemanduan bakat dan pengembangan atlet sejak usia muda dan ditangani secara tepat akan dapat berhasil dibandingkan apabila mulainya telah terlambat. Pemanduan bakat di Klub-klub panahan di Kabupaten Sleman masih belum teridentifikasi secara menye- luruh karena baru melihat pada satu aspek saja yaitu pada pencapaian skor, padahal untuk memperoleh anak yang mempunyai bakat istimewa tidak hanya dari satu aspek saja, namun aspek yang lain seperti Antropometri, Biomotor, dan kemampuan keterampilan juga ikut dipertimbangkan.

\section{KAJIAN TEORI}

\section{Pengertian Pemanduan Bakat Cabang Olahraga Panahan}

Pemanduan bakat ialah proses memilih anak yang mempunyai potensi untuk dikembangkan atau dilatih, sehingga diperoleh prestasi puncak. Menurut Siswantoyo (2009: 12) "Tujuan pemanduan bakat adalah untuk mengidentifikasi dan menyeleksi anak yang memiliki telenta yang potensial di bidang olahraga untuk dikembangkan menjadi atlet dan berprestasi secara maksimal". Proses pemilihan tersebut mengambil beberapa anak dari sekian banyak anak dengan instrumen atau beberapa tes dan pengukuran yang dapat dipertanggungjawabkan secara ilmiah. 
Melihat proses pemanduan bakat dalam prospektif yang lebih luas, tampaknya logis untuk menyarankan perubahan tertentu pada definisi 'Identifikasi Bakat'. Karena identifikasi bakat sebenarnya bagian dari kontinum, sesuai dengan tahap yang sangat khusus dalam proses yang lebih luas, tampaknya tidak tepat untuk menggeneralisasi tetapi memperlakukan sebagai tahap dalam proses pemanduan bakat. Oleh karena itu, model prinsip yang disarankan untuk pemanduan bakat dapat disajikan seperti pada gambar 1.

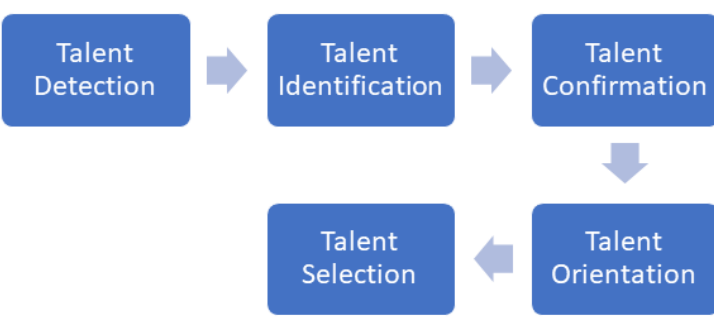

Gambar 1. Model Prinsip Pemanduan Bakat

Penjaringan terhadap anak dan remaja dengan menggunakan tes-tes jasmani, fisiologis dan keterampilan tertentu untuk mengidentifikasi potensi-potensi yang dimiliki, agar berhasil dalam aktivitas olahraga yang dipilih.
Selama ini hasil observasi menunjukkan bahwa eksistensi atlet elit selalu berkait erat dengan kerja dan waktu yang diinvestasikan para pelatih kepada calon atlet yang memiliki kemampuan alami superior. Dalam pernyataan tersebut tersirat suatu peringatan ataupun arahan agar supaya potensi, waktu dan energi yang dimiliki pelatih tidak terbuang tanpa arti dalam proses kepelatihannya, demikian juga dengan diperolehnya hasil berlatih yang jauh dari optimal, maka perlu dilakukan pemilihan calon atlet yang mempunyai kemungkinan paling besar untuk mengembangkan potensinya. Dengan demikian, dapatlah ditarik konklusi bahwa tujuan utama melakukan identifikasi calon atlet adalah untuk mengidentifikasi dan memilih calon atlet yang mempunyai kemampuan terbaik sesuai dengan cabang olahraga yang dipilih.

Tabel 1. Keuntungan Menggunakan Kriteria Ilmiah dalam Proses Identifikasi Bakat 


\begin{tabular}{|l|}
\hline Keuntungan Menggunakan Kriteria Ilmiah dalam Proses Identifikasi Bakat \\
\hline $\begin{array}{l}\text { Secara substansial mengurangi waktu yang diperlukan untuk mencapai kinerja } \\
\text { tinggi dengan memilih individu yang berbakat dalam olahraga }\end{array}$ \\
\hline $\begin{array}{l}\text { Menghilangkan volume kerja, energi, dan bakat yang tinggi di pihak pelatih. } \\
\text { Efektivitas pelatihan pelatih ditingkatkan dengan melatih terutama para atlet } \\
\text { dengan kemampuan superior }\end{array}$ \\
\hline $\begin{array}{l}\text { Meningkatkan daya saing dan jumlah atlet yang bertujuan dan mencapai tingkat } \\
\text { kinerja tinggi. Sehingga ada tim nasional yang lebih kuat dan lebih homogen } \\
\text { yang mampu meningkatkan kinerja internasional }\end{array}$ \\
\hline $\begin{array}{l}\text { Meningkatkan kepercayaan diri atlet, karena dinamika penampilannya diketahui } \\
\text { lebih hebat daripada atlet lain pada usia yang sama yang tidak melalui proses } \\
\text { seleksi. }\end{array}$ \\
\hline $\begin{array}{l}\text { Secara tidak langsung memfasilitasi penerapan pelatihan ilmiah, karena ilmuwan } \\
\text { olahraga yang membantu dalam identifikasi bakat dapat termotivasi untuk terus } \\
\text { memantau pelatihan atlet. }\end{array}$ \\
\hline
\end{tabular}

Abbott Angela Julia (2006: 4)

Ada 4 faktor yang mendorong timbulnya ketepatan; pertama, ketepatan diperoleh dari postur tubuh; kedua, pemanasan mendorong terjadinya ketepatan; ketiga, penyesuaian komponen keterampilan untuk memperoleh ketepatan gerakan; keempat, gerakan sederhana menimbulkan ketepatan. Dalam olahraga panahan setiap pemanah harus menguasai teknik dasar memanah dengan baik, sehingga penggunaan kriteria ilmiah dalam proses identifikasi bakat sangat diperlukan. Adapun keuntungan menggunakan kriteria ilmiah dapat dilihat pada tabel 1.

\section{Kebutuhan Biomotor dalam Cabang}

\section{Olahraga Panahan}

Pada dasarnya olahraga panahan merupakan gabungan dari olahraga dan seni. Disebut olahraga karena aktivitasnya menggunakan otot-otot, baik otot lokal maupun otot fungsional yang dilatih untuk membentuk komponen biomotor ability.

$$
\text { Berdasarkan pembinaan kondisi }
$$

fisik, ada komponen-komponen fisik yang lebih spesifik untuk panahan (Lee dan Robert, 2005: 144), yaitu daya tahan (endurance), kekuatan (strength), kelenturan (flexibilitas), dan structure/accura- 
cy. Dengan memiliki kekuatan otot dan daya tahan otot yang baik, maka akan memberikan keuntungan besar bagi pemanah untuk tampil di puncaknya. Di samping itu, memanah membutuhkan kekuatan otot tubuh bagian atas dan inti yang menggerakkan kelompok otot utama (Taha Zahari et al., 2018: 190).

\section{Unsur Dominan dalam Cabang}

\section{Olahraga Panahan}

1. Aspek Antropometri

Antropometri adalah salah satu aspek penting dalam mengidentifikasi bakat dari seorang pemanah. Beberapa hal yang perlu diperhatikan terkait dengan tes antropometri adalah tinggi badan, berat badan, dan rentang lengan. Sebagai contoh, pemanah yang memiliki rentang lengan yang panjang akan lebih memiliki keuntungan dalam menarik tali busur. Semakin tarikannya panjang dan kuat, maka anak panah akan melaju dengan cepat dan stabil dalam mencapai sasaran.
Tingkat berbeda yang dicapai oleh pemanah mewakili gaya sikap yang berbeda dan distribusi berat yang berbeda, yang bergantung pada postur tubuh, tinggi badan, dan struktur tulang (Ahmad Zulkifli et al., 2014: 763).

2. Aspek Fisiologis

Dalam kegiatan olahraga terutama olahraga prestasi panahan, kondisi fisik memegang peranan penting yaitu dalam meningkatkan fungsi dan sistem organisme tubuh. Otot-otot lengan yang bekerja dalam olahraga panahan terdiri dari tiga bagian yaitu otot lengan bagian atas, otot lengan bagian bawah dan otot-otot tangan. Sedangkan otot-otot yang bekerja dominan adalah otot lengan seperti otot tricep brachii, deltoids dan otot bicep brachii.

3. Aspek Keterampilan Dasar

Quan Cheng-Hao (2017: 1) bahwa konsistensi penembakan pemanah umumnya dianggap sebagai penentu penting dari skor yang berhasil. 
Teknik memanah yang tepat dan benar sangat menunjang pencapaian prestasi panahan yang optimal. Dengan dikuasainya teknik memanah yang tepat dan benar akan memungkinkan adanya keajegan (consistency) gerakan memanah baik dalam latihan maupun kompetisi. Teknik memanah bagi pemula pada dasarnya ada sembilan langkah, yaitu: 1) cara berdiri (stance); 2) memasang ekor panah (nocking); 3) posisi setengah tarikan (set up); 4) menarik tali (drawing); 5) penjangkaran (anchoring); 6) menahan sikap memanah (holding); 7) membidik (aiming); 8) melepaskan anak panah (release); dan 9) gerak lanjut (follow through).

\section{METODE PENELITIAN}

Penelitian ini termasuk penelitian deskriptif kuantitatif, karena tujuan penelitian ini adalah untuk mengetahui bakat atlet panahan di kabupaten Sleman. Metode penelitian yang digunakan adalah survei dengan menggunakan tes dan pengukuran.
Populasi yang digunakan dalam penelitian ini adalah seluruh atlet usia 7-12 tahun di wilayah kabupaten Sleman yang gemar cabang olahraga panahan. Peneliti mengambil sampel dengan kriteria atlet aktif latihan di Klub Panahan di Kabupaten Sleman usia 7-12 tahun. Jumlah sampel sebanyak 40 anak.

Instrumen pada penelitian ini menggunakan tes dan pengukuran terhadap antropometri, kemampuan fisik, dan keterampilan panahan. Adapun instrumen sebagai indikator identifikasi bakat atlet yang digunakan dalam penelitian ini adalah: (a) Tes Antropometri (TB, BB, dan Rentang Lengan); (b) Tes Kemampuan Fisik (Side Learning Rest, Uji Wall Seat, Fleksibility, Tahan Nafas); dan (c) Tes Ketrampilan Memanah (6 rambahan jarak 15 m) (DIREKTORAT PK-LK, 2013).

Data yang terkumpul kemudian dianalisis dengan menggunakan teknik analisis deskriptif kuantitatif dengan cara penyajian data dengan tabel. Data yang diperoleh dinyatakan dalam ben-tuk angka 
sehingga disebut data kuan-titatif. Adapun bentuk pengategorian keberbakatan atlet cabang olahraga panahan usia 7-12 tahun di Kabupaten Sleman merupakan data akumulasi dari keseluruhan tes pengukuran yang sudah diujikan sebelumnya. Data yang sudah terkumpul kemudian ditabulasikan dan disajikan dalam bentuk tabel keberbakatan atlet panahan.

\section{PEMBAHASAN}

Panahan menjadi olahraga yang telah lama berkembang sejak ratusan tahun yang lalu. Panahan digunakan untuk berburu dan mendapatkan makanan, juga digunakan untuk perang. Pemanah membutuhkan keterampilan khusus, pemanah harus memiliki otot lengan yang kuat, koordinasi yang baik, konsentrasi yang terlatih, juga kemampuan untuk fokus pada target yang dapat diandalkan. Indonesia telah menunjukkan prestasi dalam memanah internasional (Valianto Budi, 2017: 319).

Sistem pemanduan bakat dalam cabang olahraga panahan tampaknya masih lebih banyak mengandalkan pada pendekatan pengamatan dan pengalaman pelatih, hal ini disebabkan belum ada pola pemanduan bakat yang standar yang dilakukan dalam cabang ini, misalnya pembina dan pelatih olahraga panahan di daerah, cenderung membina atlet yang berminat dalam cabang olahraga panahan yang dibinanya, tanpa memperhitungkan apakah atlet tersebut berbakat atau potensial untuk dapat ditingkatkan prestasinya dalam cabang olahraga panahan (Adhi Purnomo, 2014: 29).

Penelitian ini dilaksanakan di Kabupaten Sleman yaitu di Kids Archery Club, Selabora Panahan FIK UNY, dan di Sendangadi Archery Club. Hasil penelitian menunjukkan bahwa kemampuan atlet panahan di Kabupaten Sleman dalam kategori sangat berbakat sebanyak 5 anak $(12,5 \%)$, berbakat sebanyak 24 anak (60\%), dan cukup berbakat sebanyak 11 anak $(27,5 \%)$. Dalam keberbakatan tersebut, seperti: kekuatan otot, daya tahan otot, dan keseimbangan yang dimiliki oleh 
masing-masing pemanah menjadi komponen yang penting.

Pemanah diharuskan untuk ber-diri diam untuk jangka waktu yang cukup lama dan memiliki sikap yang benar membantu untuk menjaga keseimbangan tubuhnya untuk seluruh proses penembakan panah. Sikap yang baik dapat membantu pemanah mempertahankan stabilitasnya untuk waktu yang lebih lama dan karenanya membantu membidik papan target dengan lebih baik. Ketika tubuh stabil, tembakan pemanah akan lebih konsisten dan tidak membuat frustrasi (Ahmad Zulkifli et al, 2014: 763).

Pemanduan bakat olahraga sangat penting dilakukan, karena sebagai upaya untuk mencari bibit olahragawan yang dapat berprestasi tinggi di kemudian hari. Proses pemanduan bakat harus berkesinambungan dari tahap identifikasi, pemilihan cabang olahraga, pembinaan keterampilan dasar olahraga dan pembinaan olahraga prestasi. Dalam memandu bakat olahraga bahwa tidak setiap anak memiliki bakat olahraga, sehingga hanya anak-anak tertentu yang memiliki potensi untuk dibina dan dikembangkan lebih lanjut. Makin awal anak menunjukkan kesesuaian latihan dengan kemampuan untuk belajar, maka makin berhasil dalam menyelesaikan program latihan yang dilakukan. Hal ini akan menyebabkan anak memiliki banyak waktu untuk berlatih sebelum mencapai usia prestasi puncak dan akan memiliki pengaruh yang berakhir positif pada latihan. Oleh karena itu, dapat dikatakan bahwa penentuan bakat merupakan suatu proses penentuan kemampuan-kemampuan (pra-kondisi) prestasi, di mana anak harus memiliki kemampuan tersebut agar dapat mencapai prestasi yang tinggi dan harus menggunakan teknik-teknik diagnosis yang sesuai. Teknik-teknik yang diberikan pun harus dimulai dari yang paling sederhana terlebih dahulu, agar anak memiliki kemampuan teknik dasar panahan yang matang. Apabila Pelatih memberikan teknik tidak secara bertahap, maka anak kesulitan dalam mengikuti dan hasil teknik 
di kemudian hari juga tidak akan maksimal.

Dengan adanya model pemanduan bakat dalam memanah dapat mengidentifikasi seseorang bakat dalam memanah. Melalui model pemanduan bakat, dapat membantu pelatih panahan untuk mendapatkan atlet panahan potensial (Valianto Budi, 2017: 326).

Hasil pemanduan bakat bahwa $80 \%$ peraih medali atlet Bulgaria pada Olimpiade tahun 1976 merupakan hasil melalui proses pemanduan bakat. Hasil yang sama ditunjukkan oleh atlet Rumania dan Jerman Timur pada Olimpiade tahun 1972, 1976, dan 1980 kesuksesannya dipercaya karena proses seleksi keilmuan yang diadopsi pada akhir tahun 1960-an (Bompa, 1994). Berdasarkan penelitian di lapangan, ternyata masih banyak para pelatih dan atlet yang belum mengetahui cara melakukan identifikasi keberbakatan panahan. Untuk itu, diperlukan kegiatan seperti coaching clinic yang di dalamnya terdapat materi terkait Pemanduan Bakat
Panahan, sehingga harapan untuk meraih prestasi ke kancah Internasional/Olimpiade semakin terbuka lebar.

\section{KESIMPULAN}

Identifikasi bakat istimewa panahan penting dilakukan oleh para pelatih, agar mendapatkan atlet yang potensial sehingga meriah puncak prestasi. Ada 3 aspek yang diperlukan dalam identifikasi bakat istimewa, yaitu (1) aspek antropometri, (2) aspek fisiologis, dan (3) aspek keterampilan dasar. Dengan masih adanya pelatih yang belum banyak mengetahui cara melakukan identifikasi keberbakatan istimewa, maka di lapangan lebih diperluas dalam sosialisasi instrumen keberbakatan olahraga panahan.

\section{DAFTAR PUSTAKA}

Adhi Purnomo. (2014). Model pengembangan pemanduan bakat olahraga panahan pegawai tetap pada kementrian pemuda dan olahraga Republik Indonesia. Journal of Physical Education, Health and Sport. http://journal.unnes.ac.id/nju/index. php/jpehs.

Abbott Angela Julia. (2006). Talent identification and development in 
sport. Department of Physical Education, Sport and Leisure Studies. Edinburgh University.

Ahmad Zulkifli, Taha Zahari, Hassan Hasnun Arif, Hisham Mohd Azrul, Johari Nasrul Hadi and Kadirgama Kumaran. (2014). Biomechanics measurements in archery. Journal of Mechanical Engineering and Sciences (JMES) ISSN (Print): 2289-4659; e-ISSN: 2231-8380; Volume 6, pp. 762-771, June 2014 (C) Universiti Malaysia Pahang, Malaysia

DOI: http://dx.doi.org/10.15282/jmes.6.2 014.4.0074.

Bompa, T.O. (1994). Theory and methodology of training; the Key to Athletic Training, Champaign: Human Kinetics.

Direktorat PK-LK. (2013). Pedoman identifikasi pemanduan bakat istimewa cabang olahraga panahan. Jakarta.

Krasilshchikov Oleksandr. (2011). Talent recognition and development elaborating on a principle model. International Journal of Developmental Sport Management Vol. 1(1) 2011. Exercise \& Sports Science Programme School of Health Sciences Universiti Sains Malaysia.

Lee dkk. (2000). "Standar Baku Teknik Memanah". Makalah Penataran
Pelatih Panahan Tingkat Dasar. Jakarta: PB. Perpani.

Quan Cheng-Hao, Din Zia Mohy-Ud, and Lee.Sangmin (2017). Analysis of shooting consistency in archers: a dynamic time warping algorithmbased approach. Hindawi Journal of Sensors Volume 2017, Article ID 7471217,6 pages https://doi.org/10.1155/2017/74712 17.

Siswantoyo. (2009). Pemanduan bakat olahraga. Fakultas Ilmu Keolahragaan. UNY.

Tahaa Zahari, Musaa, B. Rabiu Muazu, Majeeda Anwar P.P. Abdul, Alima Muhammad Muaz, Abdullah Mohamad Razali. (2018). The identification of high potential archers based on fitness and motor ability variables: a support vector machine approach. Human Movement Science 57 (2018), 184-193.

Valianto Budi, Ibrahim, Verawati Indah. (2017). The development of training and coaching centre of archery in North Sumatera. proceedings of international conference on innovation in education, science, and culture (ICIESC-2017) Medan, Indonesia, 9-10 Nov 2017. 